See Article page 14.

\section{Commentary: Rainmaking the "next-generation transcatheter aortic valve implantation" by anointing multidisciplinary perceptions}

\author{
Devendra K. Agrawal, PhD (Biochem), PhD (Med \\ Sci), MBA, and Finosh G. Thankam, PhD
}

Transcatheter aortic valve implantation (TAVI) has been the standard management strategy for aortic stenosis (AS) owing to its durability and fidelity, even in the patients with greater procedural risk. ${ }^{1}$ Introduced in 2002 by Cribier and colleagues, ${ }^{2}$ TAVI has revolutionized the care of patients with AS, as evident by drastic increase with success stories of the patients ( $>300,000$ annually) who have undergone TAVI procedure. However, the risk of complications including stroke, concomitant coronary artery diseases, and postoperative lifelong antithrombotic therapeutic regimen offer serious challenges in TAVI-based management strategies. ${ }^{3}$ Even though the outcomes of TAVI are encouraging, the information regarding the fate of TAVI beyond 5 years remains obscure. ${ }^{4}$ Interestingly, these hurdles are not a limiting factor for TAVI; however, they pave multiple ways for refining the technology to explore alternative modalities for treating the patients with impaired vascular anatomy. In fact, the present-generation TAVI is the fruit of a progressive evolution, especially in the

\footnotetext{
From the Department of Translational Research, Western University of Health Sciences, Pomona, Calif.

The research work of Dr Agrawal is supported by research grants R01HL128063, R01 HL144125, and R01HL147662 from the National Institutes of Health. The content of this article is solely the responsibility of the authors and does not necessarily represent the official views of the National Institutes of Health.

Disclosures: The authors reported no conflicts of interest.

The Journal policy requires editors and reviewers to disclose conflicts of interest and to decline handling or reviewing manuscripts for which they may have a conflict of interest. The editors and reviewers of this article have no conflicts of interest.

Received for publication June 20, 2020; revisions received June 20, 2020; accepted for publication July 2, 2020; available ahead of print Aug 3, 2020

Address for reprints: Devendra K. Agrawal, PhD (Biochem), PhD (Med Sci), MBA, Department of Translational Research, Western University of Health Sciences, 309

E Second St, Pomona, CA 91766-1854 (E-mail: DAgrawal@WesternU.edu). JTCVS Open 2020;3:25-6

2666-2736

Copyright (C) 2020 The Authors. Published by Elsevier Inc. on behalf of The American Association for Thoracic Surgery. This is an open access article under the CC BY-NCND license (http://creativecommons.org/licenses/by-nc-nd/4.0/).

https://doi.org/10.1016/j.xjon.2020.07.001
}

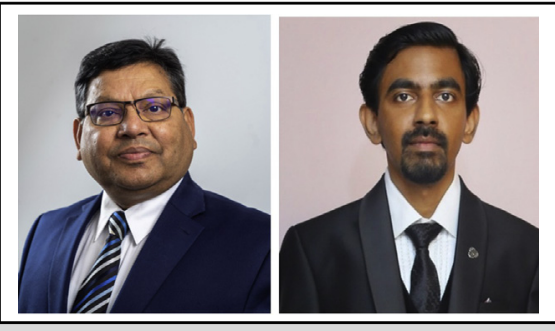

Devendra K. Agrawal, PhD (Biochem), PhD (Med Sci), MBA, and Finosh G. Thankam, PhD

\section{CENTRAL MESSAGE \\ A multidisciplinary approach of decellularization, immunologi- cally modified $\alpha$-galactosidase, and 3D-printing technology im- proves the performance of next- gen TAVI.}

simplification of procedures, sophistication of valve and catheter technologies, incorporation of preprocedural planning using computed tomography imaging, and automation, ensuring the capability to predict the potential complications. ${ }^{1}$ As the TAVI research continues, novel concepts, modifications, and inventions are emerging and proceeding towards perfection.

Application of the mechanical valve is limited, owing to the potential risk of bleeding due to the lifelong prophylactic anticoagulant medication administered to minimize thrombus formation. In contrast, the in vivo structural alterations in the biological valve increase the likelihood of reoperation. Interestingly, the advent of xenograft valves from porcine, bovine, and equine origins has significantly improved the hemodynamic profile, durability, and biological performance of TAVI. ${ }^{5}$ However, the immunogenicity of transplanted xeno-valves and subsequent peril of calcification have been an unaddressed puzzle in clinical cardiology and transplantation medicine. For instance, antigenicity of the carbohydrate moiety, galactose- $\alpha 1,3$-galactose $(\alpha$ $\mathrm{Gal}$ ), results in hyperacute immune rejection of the porcine xenograft as well as intensive calcification leading to the graft failure. ${ }^{6}$ Hence, the field of transplantation cardiology is hankering on next-generation (next-gen) xenografts to overcome such hurdles.

In this context, Lim and coinvestigators ${ }^{7}$ in the current issue of the Journal demonstrated a promising strategy to address the immunogenicity of $\alpha$-Gal and subsequent calcification in porcine TAVI using a multidisciplinary approach 


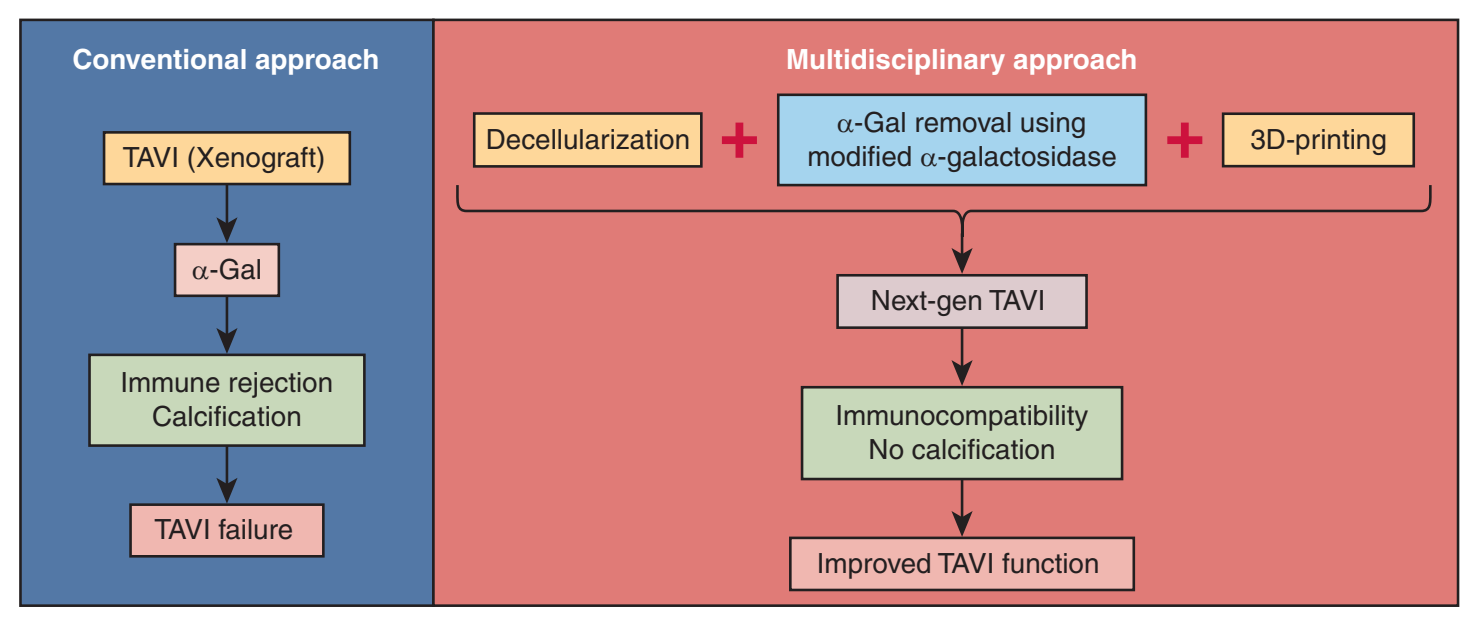

FIGURE 1. The overall stratagem demonstrating the potential advantage of multidisciplinary approach over the conventional approach in improving the performance of next-gen TAVI. TAVI, Transcatheter aortic valve implantation; $\alpha$-Gal, galactose- $\alpha 1$,3-galactose; $3 D$, 3-dimensional printing.

of decellularization, use of immunologically modified $\alpha$ galactosidase, and 3-dimensional printing technology in their TAVI-sheep model. This evolving technology is schematically shown in Figure 1 . The in vivo performance of the valves following the TAVI was exemplary, with proper stent fitting, outstanding coronary flow, better hemodynamic profile, and improved aortic valve function. Importantly, the study by Lim and colleagues ${ }^{7}$ is well appreciated for the minimal $\alpha$-Gal-triggered immune reaction and calcification over the 8-month period. In addition, the findings in a clinically relevant large animal model could be translated to humans. Certainly, their encouraging findings and multidisciplinary approach inspire the next-gen TAVI and revolutionize the management of AS. However, the study is limited by finite element analysis, insufficient simulation of biomechanics, and lack of mechanistic findings, which warrant further research before clinical trials.

Nonetheless, the findings by Lim and colleagues ${ }^{7}$ have launched a novel, multidisciplinary technological approach to improve the next-gen xenograft TAVI. In addition, imprinting the antistenotic mediators, prohealing signals, and anticalcification agents using 3-dimensional bioprinting technology would add more savor to the next-gen TAVI. Even though the findings are auspicious, the scrutiny of confounding comorbidities including hypertension and postimplantation complications including vascular injury, bleeding, and stroke warrants further attention before the translation into clinical arena. In conclusion, the multidisciplinary approach of amalgamating the elements/principles of immunology, biomaterials, molecular cardiology, and engineering would bolster next-gen TAVI, soothing the AS sufferers across the planet.

\section{References}

1. Cahill TJ, Chen M, Hayashida K, Latib A, Modine T, Piazza N, et al. Transcatheter aortic valve implantation: current status and future perspectives. Eur Heart J. 2018;39:2625-34.

2. Cribier A, Eltchaninoff H, Bash A, Borenstein N, Tron C, Bauer F, et al. Percutaneous transcatheter implantation of an aortic valve prosthesis for calcific aortic stenosis. Circulation. 2002;106:3006-8.

3. Ali N, Patel PA, Lindsay SJ. Recent developments and controversies in transcatheter aortic valve implantation. Eur J Heart Fail. 2018;20:642-50.

4. Arsalan M, Walther T. Durability of prostheses for transcatheter aortic valve implantation. Nat Rev Cardiol. 2016;13:360-7.

5. Cohen G, Christakis GT, Joyner CD, Morgan CD, Tamariz M, Hanayama N, et al. Are stentless valves hemodynamically superior to stented valves? A prospective randomized trial. Ann Thorac Surg. 2002;73:767-78.

6. Li KYC. Bioprosthetic heart valves: upgrading a 50-year old technology. Front Cardiovasc Med. 2019;6:47.

7. Lim H-G, Jeong S, Kim GB, Lee W, Son KH, Kim YJ. Next-generation transcatheter aortic valve implantation. J Thorac Cardiovasc Surg Open. 2020; $3: 14-24$. 